Revista de Journal of Integrated
GESTÃO COSTEIRA Integrada COSTAL ZONE MANAGEMENT

\title{
Model of the evolution of mounds placed in the nearshore*
}

\author{
Magnus Larson ${ }^{@,}$; Hans Hanson $^{\text {a }}$
}

\begin{abstract}
A one-dimensional mathematical model is presented that describes the cross-shore evolution of a long linear mound of noncohesive sediment placed in the nearshore and exposed to non-breaking waves. The equation for the transport rate accounts for wave asymmetry and gravity, and the net rate is expressed by reference to an equilibrium profile shape. Simplifications reduce the governing equation for mound evolution to the diffusion equation, for which analytical solutions are available for various initial shapes of the mound. Temporal and spatial dependencies governing mound evolution are obtained from the analytic solutions; for example, a doubling of the wave height implies a certain mound response in 1/8 of the time compared to the original conditions. The governing equation is also solved numerically in order to avoid schematization of the forcing, initial, and boundary conditions. Both the analytical and numerical models are compared with data on mound evolution from several sites around the world. Model predictions agree with trends in measurements of four mounds at widely different sites. An example is given concerning the application of the analytical model for preliminary mound design. The formulation presented also applies to infilling of dredged trenches with lengths much greater than their widths.
\end{abstract}

Keywords: sediment transport, dredging, profile evolution, beach nourishment, mound design

\section{Resumo $^{\S}$}

\section{Modelação da evolução de bancos de areia na zona costeira}

A evolução morfodinâmica de um banco de areia existente na zona costeira do oceano antes da zona de rebentação é descrita recorrendo a um modelo matemático unidimensional. As taxas de transporte sedimentar são calculadas relativamente a um perfil de equilíbrio e têm em consideração a assimetria das ondas e o termo gravitacional. A equação de balanço que rege a evolução da morfologia do fundo, sob certas hipóteses, reduz-se a uma equação de difusão que tem solução analítica conhecida para diferentes configurações do banco. A evolução espaço temporal do banco de areia é determinada em função de diferentes parâmetros a partir da solução analítica: por exemplo, verifica-se que a duplicação da altura da onda conduz a uma evolução mais rápida da morfologia do banco (em 1/8 do tempo) relativamente à situação de referência. Para condições mais gerais das condições iniciais, das condições de fronteira e dos forçamentos, a equação é resolvida numericamente. Ambas as soluções, analítica e numérica, são comparadas com dados que reportam a evolução de bancos de areia de diferentes locais no mundo. Os resultados obtidos mostram que os modelos descrevem a tendência das observações efetuadas em quatro bancos de areia distintos. Como exemplo de aplicação, o modelo analítico desenvolvido é considerado no projeto preliminar de um banco de areia. A formulação apresentada pode também ser aplicada para estudar a evolução da morfologia de escavações resultantes de dragagens com uma configuração em que o seu comprimento é maior do que a sua largura.

Keywords: transporte de sedimentos, dragagem, evolução de perfil, alimentação artificial, projeto de banco de areia

(a) Corresponding author, to whom correspondence should be addressed.

a Lund University, Department of Water Resources Engineering, Box 118, S-221 00 Lund, Sweden. E-mails: Larson Magnus.Larson@tvrl.lth.se; Hanson<Hans.Hanson@tvrl.1th.se>

* Submission: 25 JUN 2014; Peer review: 19 AUG 2014; Revised: 2 MAR 2015; Accepted: 3 MAR 2015; Available on-line: 5 MAR 2015

$\S$ Translation of title, abstract and captions by Paulo Silva on behalf of the authors and the Editorial Board
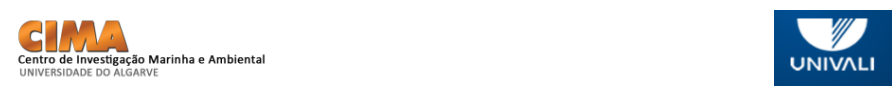


\section{Introduction}

Placement of material in the nearshore is an economical alternative for bypassing of material dredged as part of inlet channel maintenance and for maintaining beaches. Material placed in the nearshore need not be exactly compatible with that on the beach, because sorting by waves and currents will tend to move coarser sediments onshore and finer sediments offshore. Different strategies exist for nearshore sand placement, including shoreface nourishment (Van Duin et al., 2004; Grunnet et al., 2005) and the placement of sand as an offshore mound (bar), where the latter method will be investigated here. Recognizing the positive attributes of linear bars for serving as a reservoir of sand in promoting beach growth, as well as their wave dissipation function, reports on nearshore mound performance have been given by, for example, Zwamborn et al. (1970), McLellan (1990), Otay (1995), Foster et al. (1996), and Barnard et al. (2006).

Although material placed within the nearshore becomes part of the littoral system, benefits to the beach have not been well quantified. If a nearshore mound is intended to be stationary, it is referred to as stable whereas if it designed to move, it is called active (Hands and Allison, 1991; Beck et al., 2012). Here, a mound is regarded as stable if the cross-shore sediment transport is sufficiently small to induce only negligible changes in the mound shape according to a predefined criterion (for example, over 10 years). Movement of an active mound can take place as translation of its center-ofmass (across shore and alongshore) and significant dispersion or deflation in relief (e.g., Smith and Gailani, 2005). In the present study it is assumed that the mound consists of sand, whether it is stable or active. Furthermore, the study specifically considers mounds subjected to transport by non-breaking waves, that is, mounds placed offshore and seaward of the surf zone where the cross-shore morphological development is dominated by non-breaking wave conditions. Such mounds are alternatively referred to as offshore mounds. Since longshore transport gradients are not considered, the analysis presented is most applicable to mounds that are constructed as long, linear, shoreparallel bars where changes primarily take place across the shore.

The objective of this study is to derive and validate a simple cross-shore model for estimating the response of mounds constructed of dredged material, typically of sand, to non-breaking waves. Such a model would be useful for preliminary design of offshore mounds as well as for estimation as to whether a specific mound is active or stable. It is assumed that the main mechanisms controlling the sediment transport are wave asymmetry and gravity. A transport equation based on the bed-load formula proposed by Madsen $(1991,1993)$ is employed and combined with the sand volume conservation equation to yield a diffusion-type equation for the mound evolution. After further simplification, analytical solutions are obtained that provide insight for preliminary design of mounds. The transport formula is also incorporated in a numerical model to solve the full equations without approximations in a general model of profile evolution. A numerical approach will allow for a more detailed evaluation of different mound designs, although this is not explored in the present study.

A derivation of the sediment transport equation for describing the transport rate under non-breaking waves, accounting for wave asymmetry and gravity, is provided first. The transport equation is combined with the sand volume conservation equation to yield a diffusion equation from which analytical solutions can be obtained. These solutions reveal characteristic parameters that describe the main features of mound response to local wave forcing. Four applications (Silver Strand, California; Cocoa Beach and Perdido Key, Florida; and Maunganui Beach, New Zealand) are then given, where the diffusion model is employed to describe temporal mound response using the diffusion coefficient as a fitting parameter. An expression for the diffusion coefficient is derived based on the analysis for these sites. Subsequently, an example illustrating preliminary design of an offshore mound, using analytical solutions to the diffusion model, is discussed. The mound evolution is also simulated for the Silver Strand and Cocoa Beach cases with an existing numerical model (see Larson and Kraus, 1989), which was extended to numerically solve the sediment transport equation for the mound. By employing the numerical model, schematizations carried out in the analytical model regarding forcing, initial, and boundary conditions are avoided and a more realistic evolution is obtained, especially regarding the spatially varying sediment diffusion around the mound.

\section{Equation for sediment transport in the offshore}

It is assumed that the sediment transport in the offshore, seaward of the surf zone, is mainly a function of wave asymmetry and gravity (compare Niedoroda et al., 1995). The wave asymmetry tends to produce net onshore transport, whereas gravity contributes to the offshore transport. If there is a balance between these two mechanisms, an equilibrium slope is obtained where the onshore transport due to asymmetry corresponds to the tendency for increased offshore transport due to gravity. In order to develop a sediment transport equation for the mound, the bed load formula by Madsen (1991, 1993 ) is used as a starting point. Thus, the instantaneous bed-load transport rate per unit width $\left(q_{B}\right)$ may be expressed as, 


$$
\frac{q_{B}}{\sqrt{(s-1) g d} d}=\frac{8}{1+\frac{\tan \beta}{\tan \phi_{m}}}\left(|\psi(t)|-\psi_{c r, \beta}\right)^{3 / 2} \frac{\tau_{b}}{\left|\tau_{b}\right|}
$$

where $s\left(=\rho_{\mathrm{s}} / \rho\right)$ is the specific gravity of the sediment, $g$ acceleration due to gravity, $d$ the sediment diameter, $\beta$ the local beach slope $(=\partial h / \partial x$; positive if the waves propagate upslope), $\phi_{\mathrm{m}}$ the friction angle for a moving grain, $t$ time, and $\psi$ the Shields parameter defined as,

$$
\psi(t)=\frac{\tau_{b}(t)}{\left(\rho_{s}-\rho\right) g d}
$$

where $\tau_{\mathrm{b}}$ is the instantaneous bed shear stress and $\rho_{\mathrm{s}}$ and $\rho$ are densities for sediment and water, respectively. The subscript $c r, \beta$ refers to incipient conditions for sediment movement at the slope b. Although Eq. 1 was specifically developed for bed load transport, the overall dependence on the shear stress to the power $3 / 2$ has often been used to calculate the total load, which may give the equation derived in the following more general applicability.

In order to determine the net transport during a wave cycle, the instantaneous transport rate is integrated separately for the period of onshore transport $\left(q_{B, o n}\right)$ and offshore transport $\left(q_{B, o f f}\right)$. Taking offshore transport to be positive ( $x$-axis positive pointing offshore), the net transport during a wave cycle becomes $q_{B, \text { net }}=q_{B, o f f}-q_{B, o n}$. Thus, the net transport may be expressed as,

$$
q_{B, \text { net }}=A_{B}\left(\frac{I_{o f f}}{\tan \phi_{m}-\partial h / \partial x}-\frac{I_{o n}}{\tan \phi_{m}+\partial h / \partial x}\right)
$$

where $A_{B}\left(=8 \sqrt{(s-1) g d} d \tan \phi_{m}\right)$ is a coefficient that depends on the sediment properties and the integrals are defined by,

$$
\begin{aligned}
& I_{o n}=\frac{1}{T} \int_{0}^{t_{o}}\left(|\psi(t)|-\psi_{c r, \beta}\right)^{3 / 2} d t \\
& I_{o f f}=\frac{1}{T} \int_{t_{o}}^{T}\left(|\psi(t)|-\psi_{c r \beta}\right)^{3 / 2} d t
\end{aligned}
$$

where the shear stress is onshore directed when $0 \leq t \leq t_{o}$ and offshore directed when $t_{o}<t \leq T$. At equilibrium $q_{B, o n}=q_{B, o f f}$, leading to the following expression for the local equilibrium beach slope $\left(d h_{e} / d x\right)$, after rearranging Eq. 3:

$$
\frac{d h_{e}}{d x}=\frac{I_{o n}-I_{o f f}}{I_{o n}+I_{o f f}} \tan \phi_{m}
$$

Using Eq. 6, Eq. 3 may be expressed as after some manipulation:

$$
q_{B, n e t}=A_{B}\left(I_{o n}+I_{o f f}\right)\left(\frac{\partial h}{\partial x}-\frac{d h_{e}}{d x}\right)
$$

In order to employ Eq. 7 for calculating the net transport, the variation in shear stress during a wave cycle must be specified to determine $I_{\text {on }}$ and $I_{\text {off }}$ (see Eqs. 4 and 5). Also, to include the effects of wave asymmetry a higher-order wave theory should be employed. In the simplified approach taken here, the shear stress will be directly related to the bottom orbital velocity $\left(u_{b}\right)$ according to $\tau_{b}=\frac{1}{2} f_{w} \rho u_{b}^{2}$, where $f_{w}$ is a friction factor. Wave asymmetry will be described by two sinusoidal with different peak values $\left(u_{p}\right.$ for the positive onshore part of the flow when $0 \leq t \leq t_{o}$, and $u_{n}$ for the offshore negative part of the flow when $t_{o}<t \leq T$ ). Neglecting the critical shear stress for incipient motion in Eqs. 4 and 5, the integrals may be solved by replacing the shear stress with the velocity, using the appropriate amplitudes, yielding the following expression,

$$
I_{o n}+I_{o f f}=C_{B} \frac{1}{T}\left(u_{p}^{3} t_{o}+u_{n}^{3}\left(T-t_{o}\right)\right)
$$

where $C_{B}\left(=4 /(3 \pi)\left(f_{w} /(2(s-1) g d)\right)^{3 / 2}\right)$ is a coefficient that depends on the sediment properties. If the asymmetry is not too strong, the sum of the integrals in Eq. 8 may be approximated by $I_{o n}+I_{o f f}=C_{b} u_{o}^{3}$, where $u_{o}=\left(u_{p}+u_{n}\right) / 2$. For simplicity, $u_{o}$ is taken to be the bottom orbital velocity as given by linear wave theory.

Thus, Eq. 7 may be written,

$$
q_{B, n e t}=K_{c} \frac{u_{o}^{3}}{g}\left(\frac{\partial h}{\partial x}-\frac{d h_{e}}{d x}\right)
$$

where $K_{c}\left(=A_{B} C_{B}\right)$ is a coefficient that in practice will be used for calibration of the model. Thus, the net transport rate is proportional to bottom orbital velocity cubed and the deviation from the equilibrium slope. The transport model may be compared to a formula given by Kobayashi (1982) for computing trench infilling by bedload transport on a gently sloping bottom.

\section{Analytical solution to offshore mound response}

\subsection{General Solution}

The sediment transport relationship for the offshore (Eq. 9), in combination with the sand volume conservation equation, may for certain conditions be simplified so that analytical solutions can be obtained for the profile evolution around the mound. Analytical solutions, although describing idealized situations, are useful for determining combinations of parameters that govern the characteristic time and space scales of profile response. These quantities can be employed for first-order estimates of profile response or for preliminary design of offshore mounds. If the transport equation is combined with the sand volume conservation equation and certain simplifications made, a diffusion equation will result for which analytical solutions are available. 
Assuming that the bottom orbital velocity is approximately constant $\left(u_{o}=u_{o c}\right)$ in the area of interest, and expressing the response of the mound with respect to the equilibrium beach profile (EBP), with $\Delta z=h_{e}-h$ being the height of the mound over the EBP, yield the sediment transport equation:

$$
q_{B, \text { net }}=-K_{c} \frac{u_{o c}^{3}}{g} \frac{\partial \Delta z}{\partial x}
$$

The selection of a suitable value on $u_{o c}$ for field conditions will be discussed in connection with data comparison. In order to compute mound response to wave action, Eq. 10 is combined with the sand volume conservation equation given by:

$$
\frac{\partial \Delta z}{\partial t}+\frac{\partial q_{B, n e t}}{\partial x}=0
$$

Substituting Eq. 10 into Eq. 11 yields,

$$
\frac{\partial \Delta z}{\partial t}=\varepsilon_{d} \frac{\partial^{2} \Delta z}{\partial x^{2}}
$$

where:

$$
\varepsilon_{d}=\frac{K_{c} u_{o c}^{3}}{g}
$$

Equation 12 is formally identical to the diffusion equation, and analytical solutions are available that cover a large number of initial and boundary conditions. Larson et al. (1987) presented several such solutions for the one-line model of shoreline change, which reduces to the diffusion equation under certain assumptions. They discussed previously published and new solutions related to the shoreline evolution resulting from the placement of a beach fill in the nearshore such that the shoreline is initially out of equilibrium with the wave climate. Several of the solutions for shoreline change have direct analogies with mounds (or, alternatively, dredged linear trenches) in the offshore. Under the assumption that Eq. 12 is valid for describing the crossshore response of a long offshore mound (or a dredged offshore trench) placed uniformly alongshore, the solutions presented by Larson et al. (1987) for various beach fill configurations are applicable and will describe the mound (trench) evolution (see also, Kobayashi, 1982). Thus, the following general solution of the one-dimensional diffusion equation (Carslaw and Jaeger, 1959; Crank, 1973) describes the evolution of a mound (trench) in the offshore,

$$
\Delta z(x, t)=\frac{1}{2 \sqrt{\pi \varepsilon_{d} t}} \int_{-\infty}^{\infty} f(\xi) e^{-(x-\xi)^{2} / 4 \varepsilon_{d} t} d \xi
$$

where $f(x)$ is the initial shape of the mound (trench) and $\xi$ a dummy integration variable. This integral may be explicitly solved for simple mound configurations. For example, the evolution of a rectangular mound (placed on top of an existing EBP) is given by the following solution (Larson et al., 1987),

$$
\Delta z(x, t)=\frac{1}{2} \Delta z_{o}\left(\operatorname{erf}\left(\frac{a-x}{2 \sqrt{\varepsilon_{d} t}}\right)+\operatorname{erf}\left(\frac{a+x}{2 \sqrt{\varepsilon_{d} t}}\right)\right)
$$

where $\Delta z_{o}$ is the initial mound height over the sea bottom, $a$ half the mound width and erf the error function. If the initial height of the mound is given with a negative sign, the solution will instead describe the filling by cross-shore sediment transport of a long trench dug in the offshore.

\subsection{Characteristic Quantities for Mound Response}

Leading quantities governing the response of an offshore mound or trench under cross-shore sediment transport can be identified by non-dimensionalizing solutions to Eq. 12, providing insight to the governing time and space scales. Also, these quantities allow comparison of the performance of different mound designs. The evolution of an offshore mound having an initial width $a$, will be governed by the non-dimensional time scale $t^{\prime}=\varepsilon_{d} t / a^{2}$. Two mounds having the same configuration but differing in size will display the same non-dimensional evolution in time, if appropriately scaled. The control exerted by geometrical parameters on the evolution of a mound (or trench) can be assessed by comparing the non-dimensional quantities. For example, the maximum non-dimensional height of two mounds with the same initial geometric shape will be the same after time $t^{\prime}$. Translating this relationship into dimensional time yields,

$$
\frac{t_{1}}{t_{2}}=\left(\frac{a_{1}}{a_{2}}\right)^{2} \frac{\varepsilon_{d 2}}{\varepsilon_{d 1}}
$$

where the indices 1 and 2 refer to two different mounds. This equation shows that by doubling the width, a mound can withstand four times as long a period of the same wave action before experiencing the same relative decrease of the maximum height. The diffusion coefficient $\varepsilon_{d}$ enters linearly, but inversely, so that a doubling of $\varepsilon_{d}$ causes the time for the mound to experience a certain reduction to be halved. In a preliminary design situation, this equation is useful for examining the evolution of mounds with different geometric characteristics at a particular site (mounds exposed to the same wave climate). Dean (1991) reviews a similar relation for behavior of rectangular beach fill, in which the width of the fill has the same functional dependence as mound width in controlling evolution of the feature. 
By expressing $\varepsilon_{d}$ in terms of the local wave climate, the impact of the wave properties can be assessed. By linear wave theory,

$$
\varepsilon_{d}=\frac{K_{c}}{8} \frac{H^{3} g^{2} T^{3}}{L^{3}} \frac{1}{(\cosh (2 \pi h / L))^{3}}
$$

where $L$ is the wavelength, $H$ the wave height, and $T$ the wave period. Again, comparing two cases and equating the non-dimensional time $t^{\prime}$ 'gives:

$$
\frac{t_{1}}{t_{2}}=\left(\frac{a_{1}}{a_{2}}\right)^{2}\left(\frac{H_{2}}{H_{1}}\right)^{3}\left(\frac{T_{2}}{T_{1}}\right)^{3}\left(\frac{L_{1}}{L_{2}}\right)^{3}\left(\frac{\cosh \left(2 \pi h_{1} / L_{1}\right)}{\cosh \left(2 \pi h_{2} / L_{2}\right)}\right)^{3}
$$

In the case of shallow water, Eq. 18 may be further simplified to yield:

$$
\frac{t_{1}}{t_{2}}=\left(\frac{a_{1}}{a_{2}}\right)^{2}\left(\frac{H_{2}}{H_{1}}\right)^{3}\left(\frac{h_{1}}{h_{2}}\right)^{3 / 2}
$$

Equation 19 illustrates the influence of the wave height and the water depth for comparing the evolution of two mounds of identical initial shape. For example, doubling the characteristic wave height causes a mound to respond in $1 / 8$ of the time as compared to the original conditions. Similarly, placement of an offshore mound in deeper water increases the response time as depth to the $3 / 2$ power, as compared to a base condition.

\subsection{Comparison with Field Data}

Comparisons of predictions were first made to measurements from two field sites where offshore mounds were placed. Because detailed information on the forcing could be obtained for these sites, simulations with a numerical profile evolution model were also carried out (discussed further below) to examine predicted mound response without introducing the simplifications of the analytical model. In the following, short descriptions of the two data sets are given; additional information is given together with the presentation of the numerical simulation results.

Measurements of the profile through time made at a mound off Silver Strand State Park (Andrassy, 1991; Larson and Kraus, 1992) were evaluated with the diffusion model. An EBP was determined in accordance with Larson et al. (1999) and subtracted from the profile surveys to isolate the mound evolution. Wave measurements were carried out between January and May 1989 during which four surveys were taken (890119, 890215, 890315, and 890518, in YYMMDD format). These measurements were employed to derive a statistically representative value on the forcing parameter included in the diffusion coefficient used in the analytical model (see next section). The January survey was made just after construction of the offshore mound was completed. Subsequent surveys revealed that most of the material moved onshore (see Fig. 1). During this period the wave climate was mild, and no major storms were recorded. Thus, these data constitute an excellent

set for testing the analytical model (Eq. 14) developed to predict mound evolution in the offshore under nonbreaking waves. All profiles shown here were measured along Survey Line 5 (extending across the central portion of the mound; see Larson and Kraus, 1992), where longshore perturbations were judged to be the smallest. The median grain size $d_{50}$ of the placed material was $0.20 \mathrm{~mm}$.

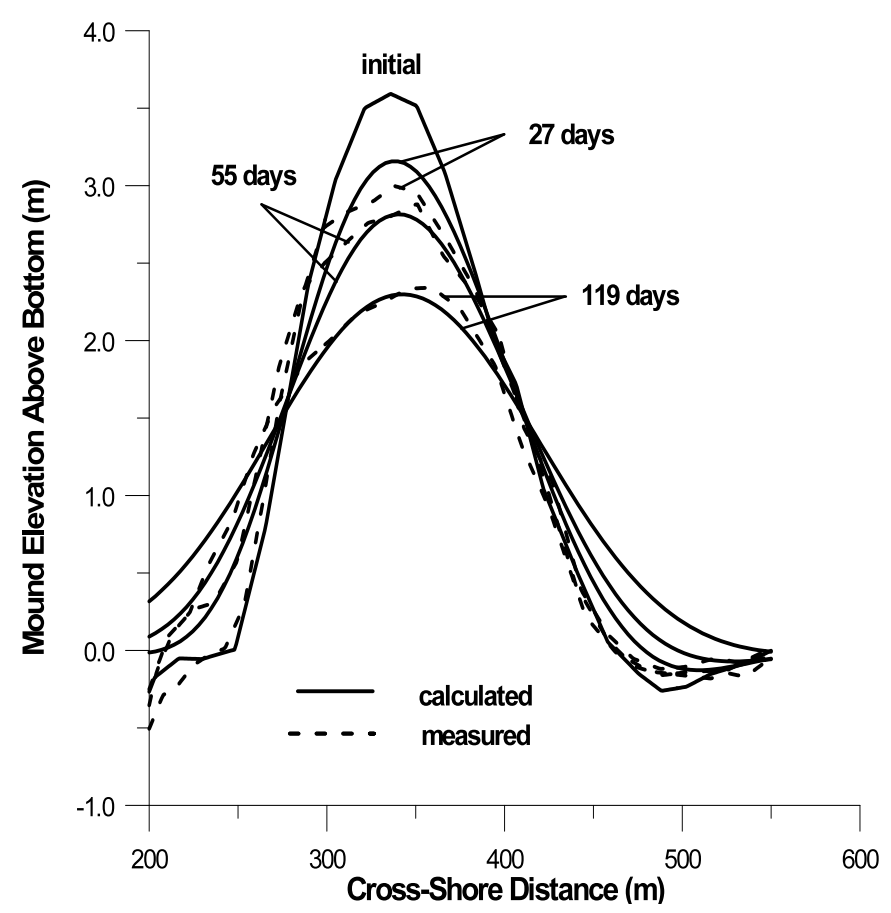

Figure 1 - Comparison of measurements and analytical solution, Silver Strand, CA

Figura 1 - Comparação entre as medições e a solução analítica, Silver Strand, $C A$

An optimum value for the diffusion coefficient, $\varepsilon_{d}=15$ $\mathrm{m}^{2} /$ day, was determined through visual fitting against the measured profiles. Fig. 1 illustrates the agreement between the measurements and analytical solution obtained by superimposing initially trapezoidal line segments as discussed by Larson et al. (1987). The surveys were carried out approximately 27, 55, and 119 days after the post-construction survey (used as the initial profile here). As seen in Fig. 1, the analytical solution produces symmetric diffusion of the mound, the result of specifying a constant diffusion coefficient (i.e., $u_{o c}$ constant). In a numerical approach, as shown below, $\varepsilon_{d}$ can be made a function of water depth, thereby producing more rapid diffusion in shallow water that better describes the skewed shape and onshore migration of the mound. However, despite various simplifications (e.g., schematization of initial, boundary, and forcing conditions) the analytical solution captures the overall response of the mound, and it can be applied to obtain 
estimates of quantities such as the decrease in the maximum mound height and reduction in mound volume, within the original boundaries of the mound.

Cocoa Beach near Cape Canaveral served as a beneficial-use site for dredged material on three occasions between June 1992 and June 1994. The first placement was carried out in June 1992 in the northern half of the authorized site (approximately between survey lines 0 and +3500 ), whereas the second and third placements were conducted over longer time periods and broader areas. Data pertaining to the first disposal were considered here for further validation of the diffusion model.

One survey was made immediately after construction of the mound followed by two surveys 136 and 291 days after the mound placement. An EBP was determined in accordance with Larson et al. (1999) and subtracted from the surveys to isolate the mound response. Evolution of Survey line 1,500 located in the central portion of the mound was analyzed, and the median grain size of the fill material was $0.14 \mathrm{~mm}$. No wave measurements were carried out in connection with the profile surveying, but a wave hindcast showed that the mound was mainly exposed to non-breaking waves during the measurement period.

Fig. 2 indicates the agreement between the analytical model of mound evolution and the measured profile. A diffusion coefficient value of $8 \mathrm{~m}^{2} /$ day produced satisfactory description of the mound response. As for the Silver Strand mound, the analytical model predicted some seaward diffusion not observed in the measurements, attributed to overestimation of $\varepsilon_{d}$ in this region. Because the evolution of the mound is described with respect to an equilibrium profile that is monotonically increasing (depth) with distance offshore, the predicted diffusion of the mound at its seaward side will always be over-predicted. The greater the vertical difference between the elevation of the equilibrium profile at the shoreward and seaward side of the mound, the larger this effect will be. However, the overall evolution of the mound is well described by the analytical solution, creating confidence in the simple diffusion model for first estimates of how the mounds placed in the offshore respond to the action of non-breaking waves.

\subsection{Dependence of Mound Diffusion on Wave Condi- tions}

In order to apply the analytical model for preliminary design of offshore mounds, it is necessary to estimate the diffusion coefficient. Although relative comparisons can be made based on the characteristic quantities presented (e.g., Eqs. 18 and 19), it is of practical value to quantify the absolute evolution of a mound. However, there are few data sets on mound evolution suitable for determining $\varepsilon_{d}$. In addition to Silver Strand and Cocoa
Beach, two other data sets were identified for analysis of $\varepsilon_{d}$. These two mounds were located at Maunganui Beach off the coast of New Zealand (Foster et al., 1996) and at Perdido Key, Florida (Otay, 1995; Work and Otay, 1996). Analysis of data from these two sites produced $\varepsilon_{d}=25$ and $1 \mathrm{~m}^{2} /$ day for Maunganui Beach and Perdido Key, respectively. Thus, fortunately, a wide range of $\varepsilon_{d}$-values was obtained in the analysis, corresponding to a variety of conditions at the different sites.

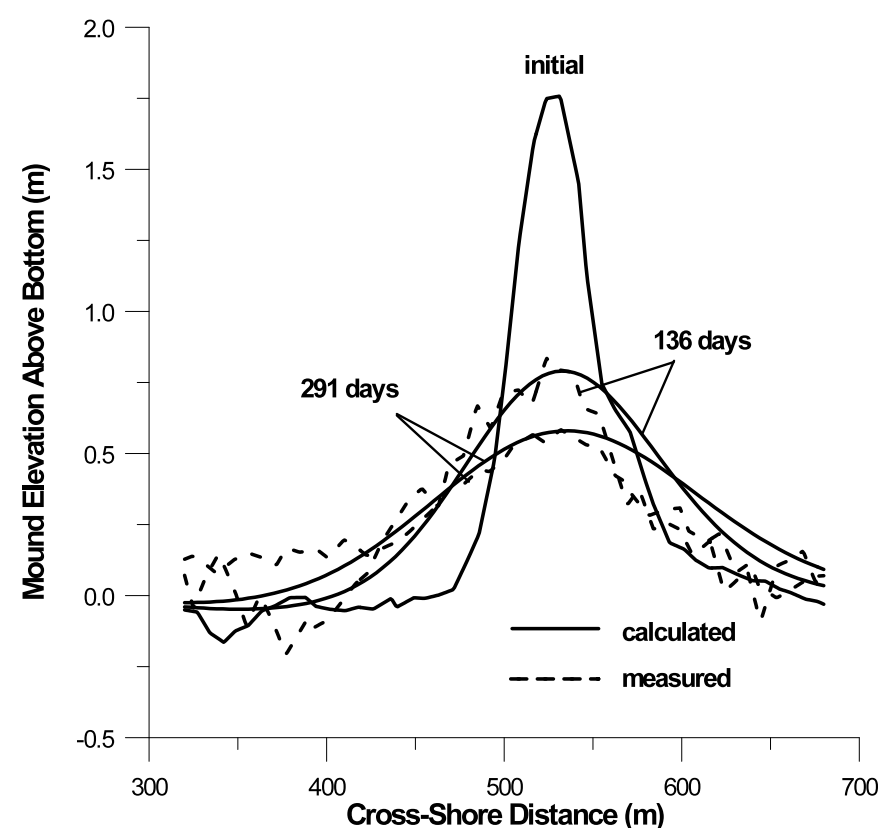

Figure 2 - Comparison of measurements and analytical solution, Cocoa Beach, FL

Figura 2 - Comparação entre as medições e a solução analítica, Cocoa Beach, Florida

Representative wave quantities at Maunganui Beach were estimated based on various data sources which reported results of wave measurements off the New Zealand East Coast (see Table 1 in Foster et al., 1996; straight-forward averaging was employed to obtain the representative wave quantities). However, Foster et al. (1996) pointed out that the data records did not contain many storms implying that the wave height might have been somewhat underestimated. At Perdido Key, wave measurements were available from two wave gages, where the longest record encompassed 4 years. Values employed here were computed from mean wave quantities reported by Otay (1995). The mean significant wave height and mean wave period $T_{a}$ obtained at the different sites were input to calculate the significant wave height $H_{s, m}$ and associated bottom orbital velocity $u_{o c, m}$ at a location corresponding to the initial maximum mound height (having the associated water depth $h_{m}$ ). Since the bottom orbital velocity to the power 3 is governing the sediment diffusion (see Eq. 13), it is probably better to work with a representative wave height based on $\overline{H_{s, m}^{3}}$ when calculating $u_{o c, m}$ (see 
Walstra et al., 2013); however, for applications at sites with limited data it is more likely that $\overline{H_{s}}$ is available compared to $\overline{H_{s}^{3}}$. Thus, this statistical measure was employed here. Thus, all wave quantities employed in this study were measured or hindcast for the period when the profile surveys were carried out, except Maunganui Beach which relied on more general estimates of the wave conditions. Table 1 summarizes the environmental conditions and sediment characteristics at the four different sites.

Table 1 - Environmental conditions for the four sites (subscript $s$ denotes significant wave height and subscript $m$ denotes quantities taken at a water depth corresponding to the peak of the initial mound).

Tabela 1 - Condições hidrodinâmicas e características dos sedimentos nos quatro bancos de areia (o subscrito s refere-se à altura significativa da onda e o subscrito $m$ refere o valor das grandezas na profundidade do cume do banco de areia inicial).

\begin{tabular}{c|c|c|c|c|c}
\hline Site & $\begin{array}{c}H_{s, m} \\
(\mathrm{~m})\end{array}$ & $\begin{array}{c}T_{a} \\
(\mathrm{sec})\end{array}$ & $\begin{array}{c}h_{m} \\
(\mathrm{~m})\end{array}$ & $\begin{array}{c}u_{c c, m} \\
(\mathrm{~m} / \mathrm{sec})\end{array}$ & $\begin{array}{c}d_{50} \\
(\mathrm{~mm})\end{array}$ \\
\hline $\begin{array}{c}\text { Silver } \\
\text { Strand }\end{array}$ & 0.78 & 8.7 & 3.8 & 0.59 & 0.20 \\
\hline $\begin{array}{c}\text { Cocoa } \\
\text { Beach }\end{array}$ & 1.26 & 8.8 & 4.7 & 0.84 & 0.14 \\
\hline $\begin{array}{c}\text { Maunganui } \\
\text { Beach }\end{array}$ & 1.33 & 9.0 & 3.5 & 1.05 & 0.29 \\
\hline $\begin{array}{c}\text { Perdido } \\
\text { Key }\end{array}$ & 0.55 & 6.3 & 3.8 & 0.39 & 0.30 \\
\hline
\end{tabular}

Equation 13 gives a theoretical relationship for the dependence of $\varepsilon_{d}$ on $u_{o c}$, and Fig. 3 shows this relationship plotted for the analyzed data sets. Although the scatter is considerable, the clear trend indicates that Eq. 13 based on the mean local wave conditions may yield predictions on $\varepsilon_{\mathrm{d}}$ that exhibit its main behavior, although the equation should be used with care and preferably a range of values on $\varepsilon_{d}$ employed to establish the variability in mound response. The bottom orbital velocity employed was calculated from the mean significant wave height at the peak of the initial mound during the measurement period. A least-square fit of Eq. 13 to the data points yielded $K_{c}=0.0024$.

Efforts were made to estimate $K_{c}$ individually for each case and to relate these $K_{c}$-values to various nondimensional parameters including grain size, but no clear relationship could be established. Presently available data are limited and do not support adoption of expressions for $\varepsilon_{d}$ that are more comprehensive than Eq. 8. The mound at Silver Strand was placed on top of a natural bar, whereas the other mounds were placed further offshore where the profile depth was monotonically increasing with distance offshore. This circumstance may have contributed to the apparent deviation of data point for Silver Strand from the overall trend of the points in Fig. 3.

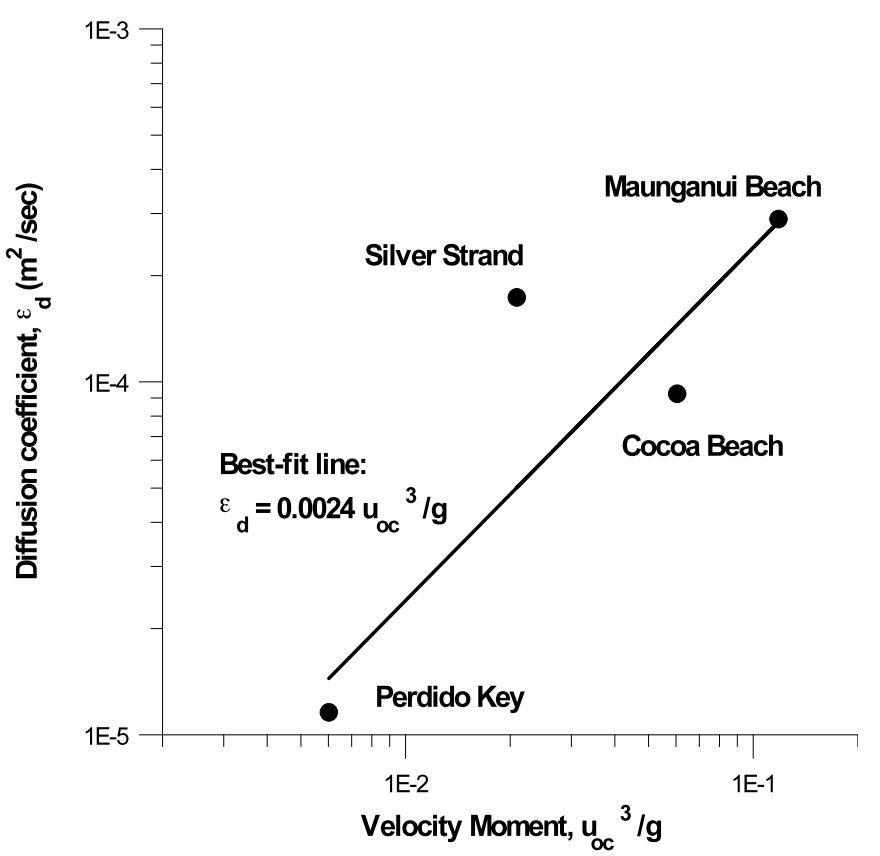

Figure 3 - Diffusion coefficient for different mounds Figura 3 - Coeficiente de difusão, $\varepsilon_{d}$, para diferentes bancos

\section{Preliminary design of nearshore mounds}

Preliminary design of mounds can be carried out based upon the analytic solutions, by which key parameters controlling mound response can be estimated. The analytical solutions were obtained through simplifications, and the limitations of these solutions should be realized. However, reasonable results were achieved for the field sites investigated; and the solutions should provide acceptable first estimates of the mound response if cross-shore sand transport under non-breaking waves is the dominant transporting mechanism. Also, the prevailing wave and sediment conditions should not deviate too much from the field cases summarized in Table 1. For detailed analysis and design of offshore mounds a numerical approach should be taken.

The solution presented by Larson et al. (1987) for a collection of line segments can be applied for any initial mound shape. Here, only the example of an initially triangular mound will be discussed (the solution for a rectangular mound is given by Eq. 15). Fig. 4 illustrates the time evolution of the non-dimensional maximum mound height and non-dimensional mound volume for a triangular mound. Height and volume were normalized with their values at time $t=0$, and the volume expresses the amount of material within the original boundaries of the mound, between $x=-a$ and $a$. With knowledge of the typical wave climate (mean significant wave height and period) and the dimensions of the mound (height and width), Fig. 4 can be entered to estimate the height and volume after a certain time. Similarly, the water depth of placement can be optimized to 
achieve a specified spread of material (i.e., volume reduction) by reference to this figure. To simplify estimation of the diffusion coefficient when applying Fig. 4, Fig. 5 was constructed by converting to deep-water wave height $H_{o}$ and wavelength $L_{o}$, and neglecting refraction. Thus, from the wave conditions in deep water, $\varepsilon_{d}$ may be estimated at any water depth through Fig. 5 .

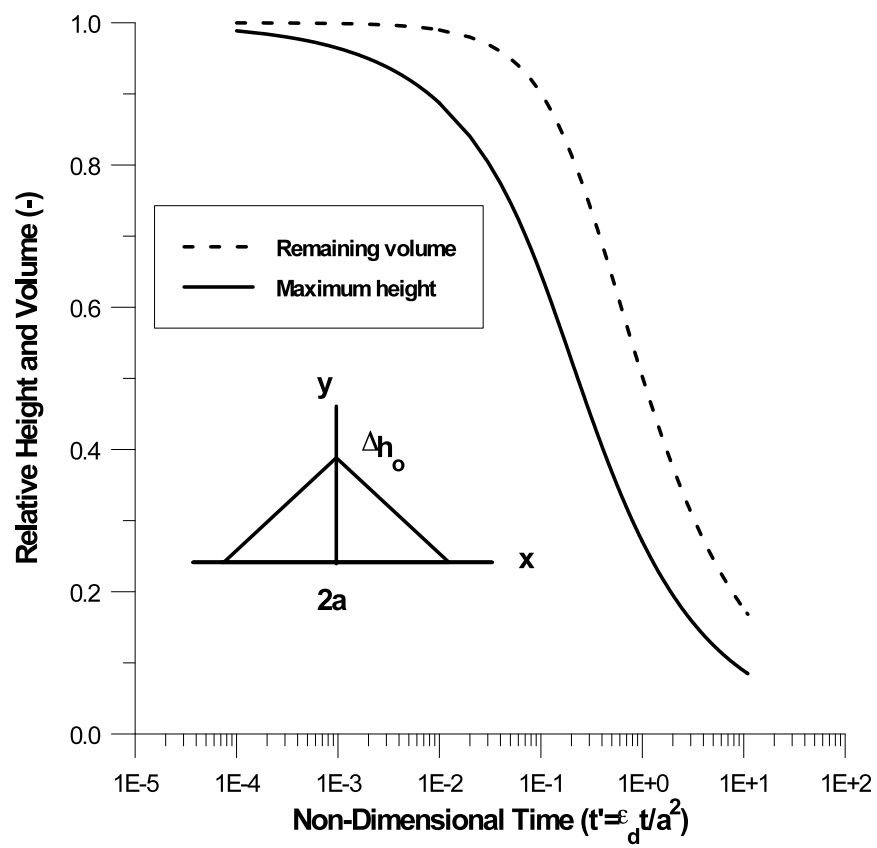

Figure 4 - Evolution of relative height and volume of initially triangular mound

Figura 4 - Evolução da altura relativa e do volume de um banco de areia triangular.

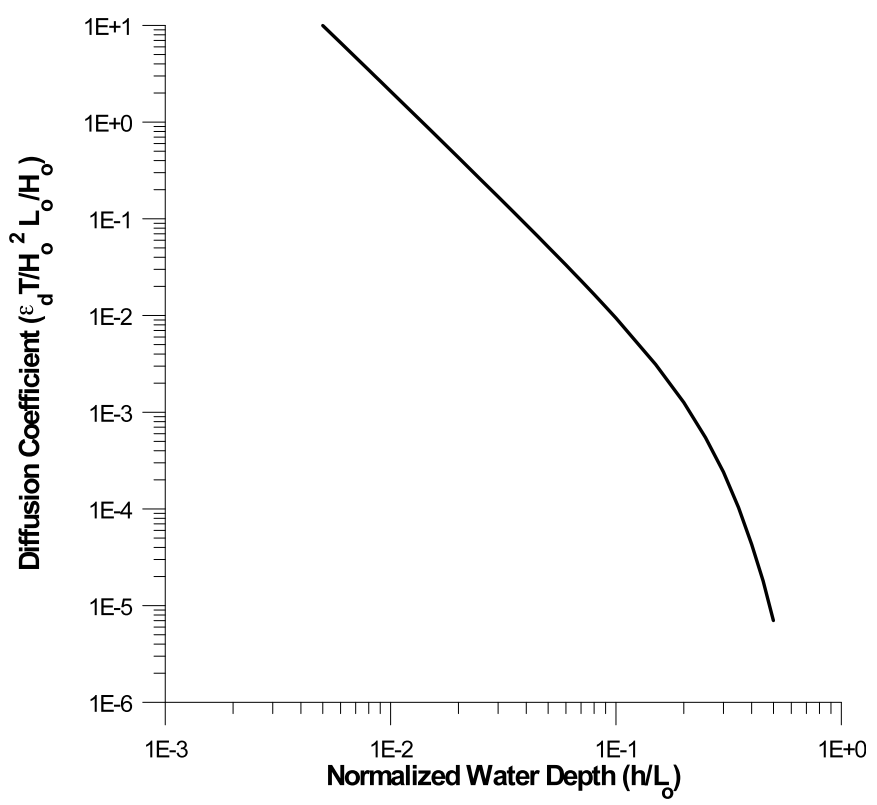

Figure 5 - Diffusion coefficient as function of normalized water depth

Figura 5 - Valores do coeficiente de difusão em função da profundidade normalizada
As an example, consider a typical U.S. East Coast wave climate with an average deep-water significant wave height of $1 \mathrm{~m}$ and average wave period of $8 \mathrm{sec}$. Placing an initially triangular mound with the peak in $h=4 \mathrm{~m}$ water depth gives $h / L_{o}=0.04$ and $\varepsilon_{d} T / H_{o}^{2} \quad L_{o} / H_{o}=0.087$ from Fig. 5. Thus, $\varepsilon_{d}$ is calculated to be approximately $1.1 \cdot 10^{-4} \mathrm{~m}^{2} / \mathrm{sec}\left(=9.5 \mathrm{~m}^{2} /\right.$ day $)$. Assuming an initial mound width of $100 \mathrm{~m}(a=50 \mathrm{~m})$, mound response after 1 month can be determined from Fig. 4. The nondimensional time is given by $t^{\prime}=9.530 / 50^{2}=0.11$. From Fig. 4 it is seen that the remaining volume $\left(\Delta V / \Delta V_{o}\right.$, where $\Delta V$ is the mound volume and subscript $o$ denotes the initial conditions) is about $90 \%$ of the volume placed originally, and the maximum height is about $60 \%$ of the initial height $\left(\Delta z / \Delta z_{o}\right)$. Fig. 4 is valid for an initially triangular mound. Other mound shapes (e.g., rectangular) would display somewhat different evolution, especially regarding the decrease in $\Delta z$. However, the evolution of the remaining volume, being an integrated quantity, is less sensitive to the initial mound shape. The analytical solutions describing the time response of the mound can be applied to design both stable and active mounds, where the stability (or activity) of the mound should be defined in terms of changes in geometric mound properties over certain time scales. Finally, it is again noted that the solutions presented are equally applicable for trenches ("negative" mounds) if the basic mechanisms controlling the sand transport and bathymetric response are the same.

\section{Numerical simulation of mound response}

\subsection{Modified SBEACH Model}

To investigate the sediment transport model for mound evolution in the offshore without the approximations necessary to arrive at analytical solutions, the model was incorporated in an existing numerical model of profile evolution and dune erosion (SBEACH; see Larson and Kraus, 1989). The original SBEACH model does not include the effects of wave asymmetry and gravity in the offshore, but the sediment transport in this region is primarily a function of seaward diffusion of sediment from the surf zone that is mainly characteristic for offshore transport and profile erosion. The main advantage of using a numerical approach is that the initial, boundary, and forcing conditions can be made arbitrary allowing for more realistic simulations (i.e., the diffusion coefficient varies in time and space). Also, the transport of material in the surf and swash zone could be incorporated, although the former was of minor importance for the transport on the mound in the cases investigated. Thus, the overall objective of the numerical simulations was to assess the applicability of the sediment transport model under more general conditions without limitations in characterizing the forcing or profile configuration. 
Two field sites (Silver Strand, CA, and Cocoa Beach, FL) where the response of offshore mounds to waves was monitored in detail were available for calibration and validation of the sediment transport model developed for the offshore. However, the equation was first generalized to random waves through a wave-bywave calculation algorithm (Dally, 1992), resulting in expressions for the mean transport rate analogous to what Larson (1996) obtained for the surf and swash zone. The sediment transport routine was then included in SBEACH to calculate the necessary hydrodynamic quantities and to predict cross-shore sediment transport rates in the surf zone (if necessary). Background information for the simulations are given in the following as well as summaries of the simulation results.

Employing a transport equation in the form given by Eq. 9 requires predictive expressions for how $h_{e}$ varies with wave and sediment properties. For the surf zone, Dean $(1977,1987)$ proposed relationships based on median grain size or sediment fall speed (see also Bruun, 1954). Larson et al. (1999) developed a predictive equation for the profile shape under nonbreaking waves, where the depth at breaking $h_{b}$ constituted the main parameter in calculating the shape ( $h_{b}$ is the shoreward boundary for the portion of the profile exposed to non-breaking waves). This equation was adopted in the present simulations to derive the local EBP slope at every time step (used in Eq. 9).

\subsection{Silver Strand, California}

The numerical model was calibrated and validated with measurements for the mound placed off Silver Strand State Park (Andrassy, 1991; Larson and Kraus, 1992). As previously described, four surveys were taken between January and May 1989, together with wave measurements. After placement, the mound diffused and most material moved onshore. Measured significant wave height, mean wave period, and mean incident wave angle were available about every three hours (in $10.9 \mathrm{~m}$ water depth) for 114 days. The water level was not recorded, but an hourly time series of tidal elevations was generated with a numerical model (DRP, 1994). The simulations started with the measured profile at 890119, and comparisons were made between calculated and measured profiles for the other three surveys. The only calibration coefficient was $K_{c}$, all other coefficients in the model were held constant in the simulations at their default values as recommended in the SBEACH manual (Rosati et al., 1993). The time step was $20 \mathrm{~min}$, and grid cell size was $10 \mathrm{~m}$. The median grain size was set at $0.20 \mathrm{~mm}$, in accordance with field samples.

Fig. 6 displays the calculated profile after the entire simulation period (890518) together with the measured initial and final profile. The coefficient $K_{c}$ was cali- brated to 0.03 by visually minimizing the difference between the final measured and calculated profile. Overall the model prediction was satisfactory, although the accumulation above mean sea level was not well described (not the focus of this study, but the entire profile shown since it is included in the simulation). This is likely a result of the model's limited ability to simulate accumulation in the swash zone. However, the actual profile probably also experienced some changes associated with longshore transport, not included in the present simulations. The diffusion of the mound, with most of the material moving onshore, was correctly reproduced similarly to the analytical model, but the possibility to vary the diffusion coefficient in time and space improved the simulated profile evolution with the numerical model.

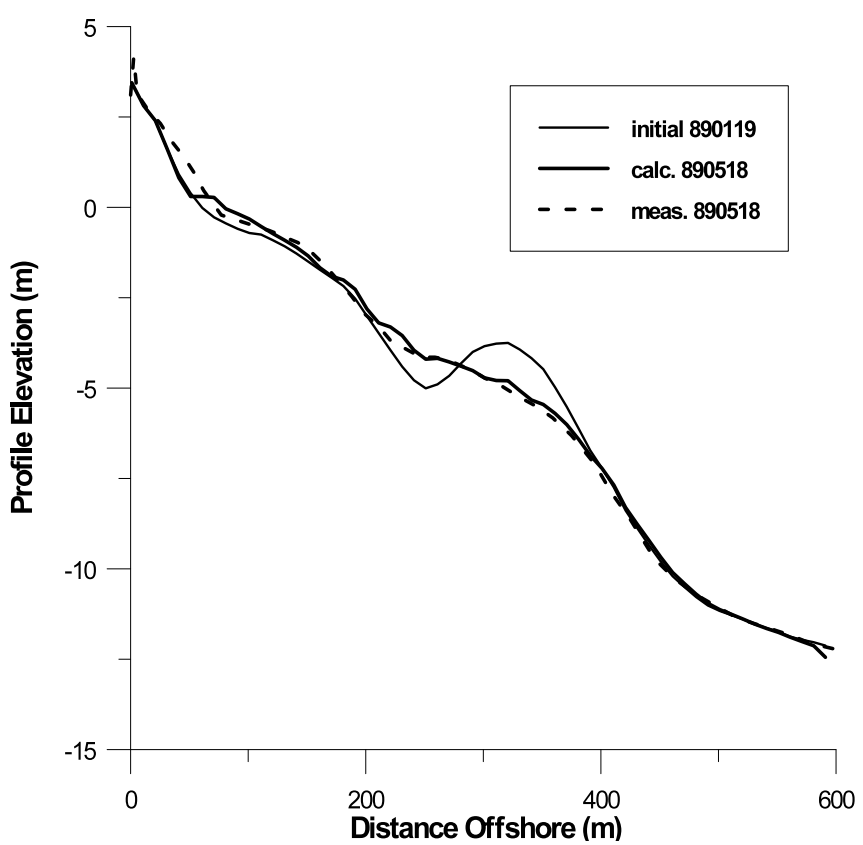

Figure 6 - Calculated and measured profiles at Silver Strand after 4 months

Figura 6 - Comparação entre o perfil simulado e o observado em Silver Strand após 4 meses

To validate the model, comparisons were made with the intermediately measured profiles, and Figs. 7 and 8 illustrate the results for surveys made at 890215 and 890315, respectively. Agreement is judged to be good, especially regarding the overall mound shape. For the survey made 890215 , the trough seaward of the mound was more pronounced in the measurements, implying that the model fills up the trough somewhat too quickly.

\subsection{Cocoa Beach, Florida}

The second case investigated with the numerical model was the mound placement at Cocoa Beach, previously simulated for the analytical model validation. The profile surveys taken off Cocoa Beach only included an area that started in about $4 \mathrm{~m}$ water depth and extended to a little more than $8 \mathrm{~m}$. Trial simulations were carried 


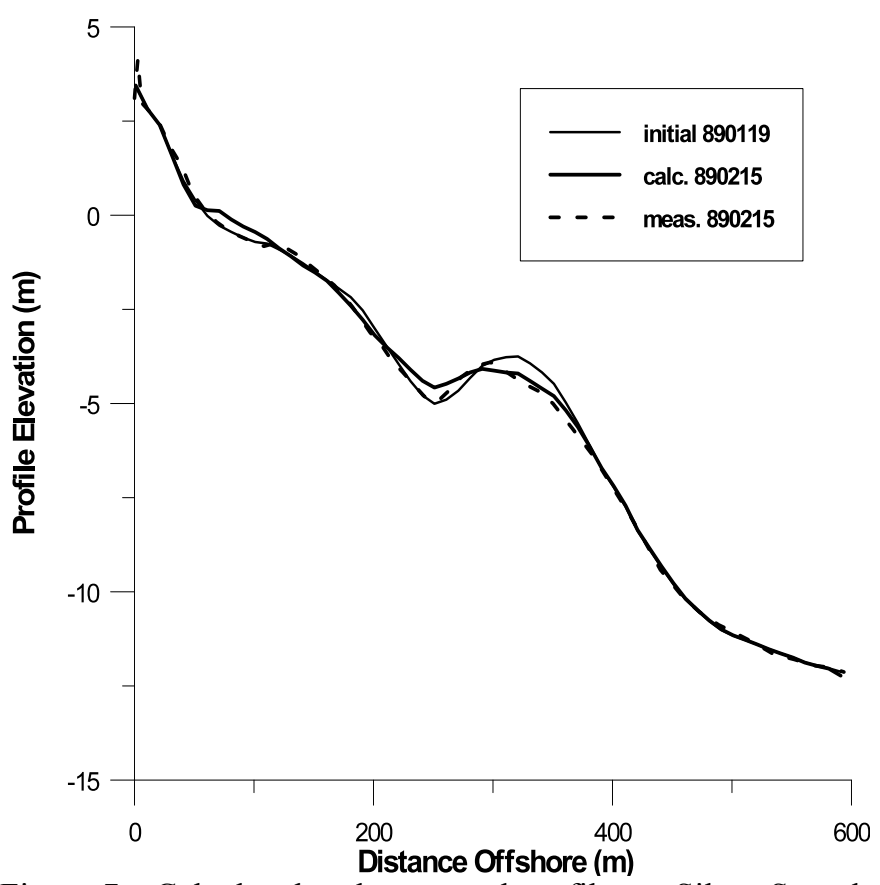

Figure 7 - Calculated and measured profiles at Silver Strand after 1 month

Figura 7 - Comparação entre o perfil simulado $e$ o observado em Silver Strand após 1 mês

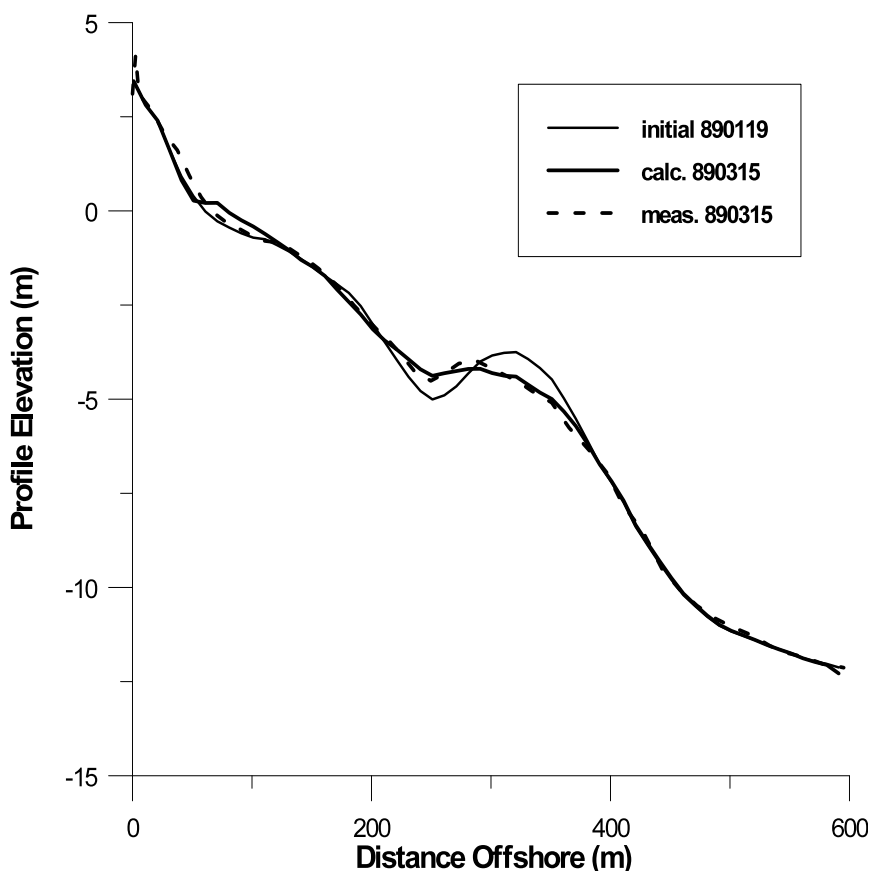

Figure 8 - Calculated and measured profiles at Silver Strand after 2 months

Figura 8 - Comparação entre o perfil simulado e o observado em Silver Strand após 2 meses

out for the surveyed area only (neglecting the inshore portion of the profile), but it proved difficult to formulate the shoreward boundary condition for such a situation and significant pile-up of material occurred at this boundary. Thus, a hypothetical profile was constructed shoreward of the survey area by linearly extrapolating the most inshore portion of the measured profile. The selected initial shape surely oversimplified the real profile configuration; however, after some simulation time the profile took on a more realistic shape. Also, the inshore shape did not markedly affect the response of the mound, although there was clear shoreward transport of material from the mound to shallower water.

A time period of about 4.5 months (920728 to 921211) was selected for the simulations where the initial profile corresponded to the post-disposal profile after the first mound placement. No wave or water level measurements were available, so numerical hindcasts were utilized. WIS wave information available every $3 \mathrm{hr}$ (10-m water depth) was combined with calculated hourly tidal elevations (DRP, 1994). It should be noted that the use of WIS data might have overestimated the wave conditions since the effect of bottom friction in the propagation from offshore to the end of the grid was not included (Dally and Osiecki, 2006). Wave angle was not included in the simulations, and the time and length steps were $20 \mathrm{~min}$ and $10 \mathrm{~m}$. A representative median grain size of $0.15 \mathrm{~mm}$ was employed in all simulations based on sediment sampling. The calculated waves across the profile demonstrated that only few waves broke in the vicinity of the mound and that the transport in this area due to the breaking waves was small.

First, the $K_{c}$-value from the Silver Strand simulations was input. However, the predictions produced onshore transport rates that seemed to yield excessively large accumulation in the inshore portion of the profile as well as a diffusion of the mound that exceeded the measurements. Thus, $K_{c}$ was re-calibrated, and a value of 0.004 was obtained as optimal for reproducing the measurements. As expected, the difference in $K_{c}$-value between Cocoa Beach and Silver Strand value agreed with the results from fitting the analytical model to the field data, which also produced a larger value on the diffusion coefficient for Silver Strand that deviated from the other studied sites. The $K_{c}$-value obtained for the Cocoa Beach simulations with the numerical model was in agreement with the overall estimate from the analytical model, indicating that this value is most likely more representative than the $K_{c}$-value from the Silver Strand simulations.

Fig. 9 illustrates the initial profile together with the final calculated and measured profiles, and Fig. 10 shows a blow-up for the portion of the profile were the measurements were carried out. The calculated inshore portion of the profile displays a shape typical of a composite EBP subject to random waves. A concave shape appears in the region where breaking waves dominate, followed by a change in the curvature going seaward as the bar region is approached and where non-breaking waves start to control the profile shape. Further seaward the profile again attains a concave shape, although in the present case the mound perturbs the profile here. 


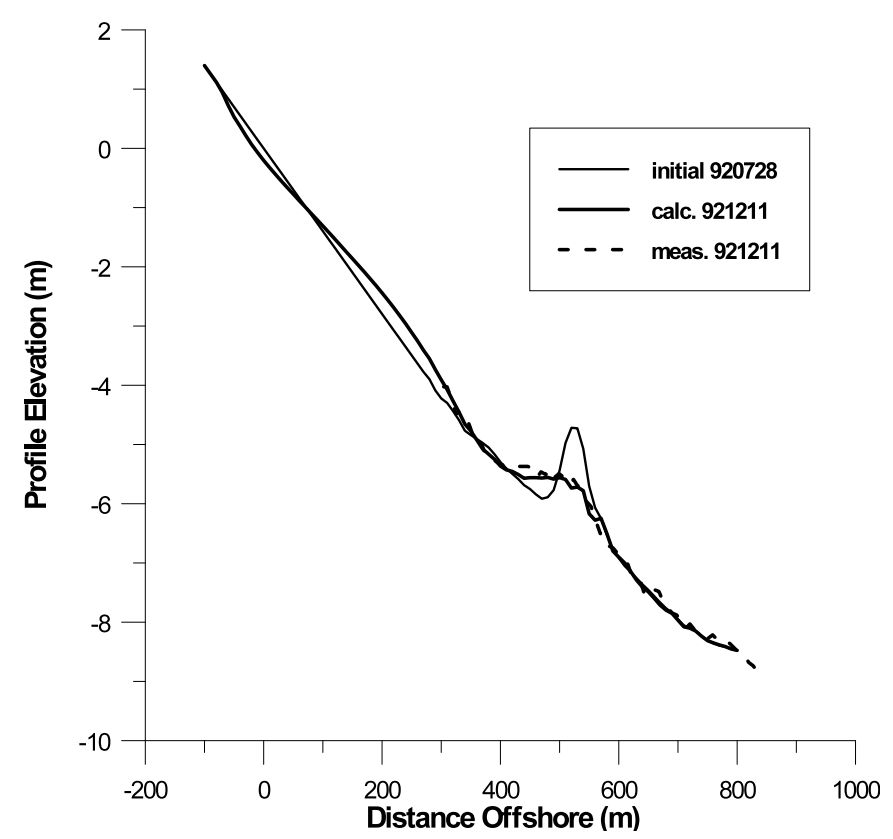

Figure 9 - Calculated and measured profiles at Cocoa Beach after 4,5 months

Figura 9 - Comparação entre o perfil simulado $e$ o observado em Cocoa Beach após 4.5 meses

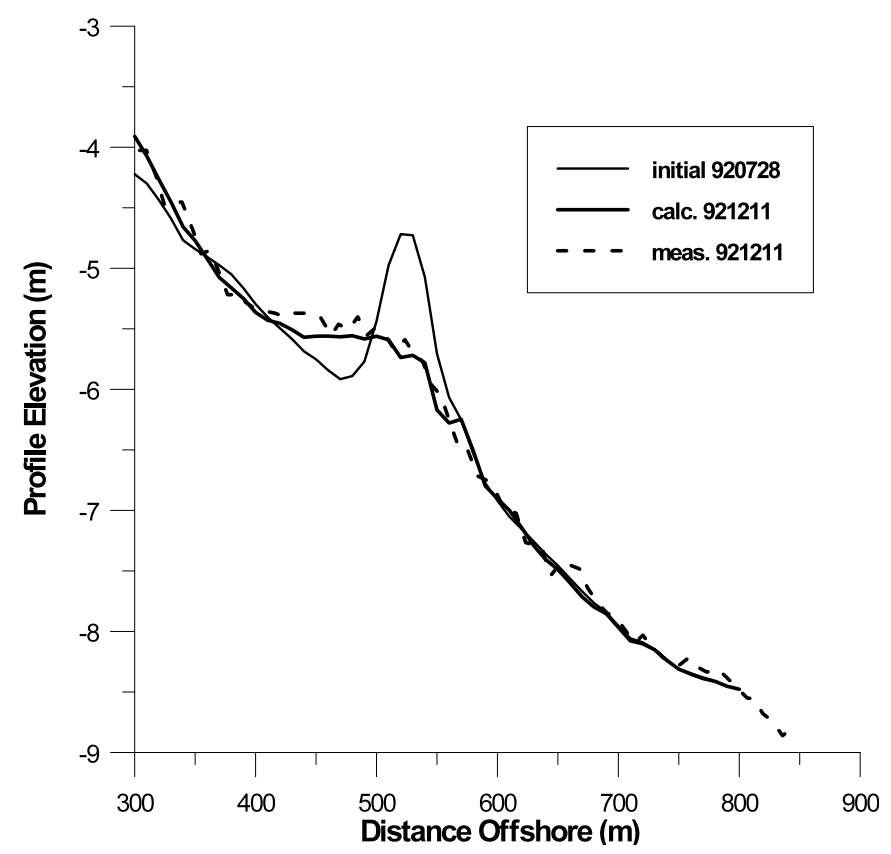

Figure 10 - Calculated and measured profiles at Cocoa Beach after 4.5 months (blow-up of Fig. 9)

Figura 10 - Comparação entre o perfil simulado e o observado em Cocoa Beach após 4,5 meses (pormenor da Figura 9)

\section{Discussion of simulation results}

The analytical model was based on marked simplifications of the governing processes and how the initial, boundary, and forcing conditions were employed in the model. In spite of this, the evolution of the mounds investigated could be well reproduced after appropriate values had been selected on a coefficient $\left(K_{c}\right)$ characterizing the mound diffusion. The mound diffusion was related to $u_{o c}^{3} / g$ and $K_{c}$ appeared as a multiplier in the expression for the diffusion coefficient. For three of the four field cases studied, $K_{c}$ attained quite similar values; however, for the Silver Strand case $K_{c}$ exhibited a significantly larger value. One possible reason for this deviation was that the mound at Silver Strand was placed in an area (on top of an existing bar) with more active sand transport, with breaking waves occasionally affecting the transport for the period of study. Overall, the relationship derived for the diffusion coefficient may be used for scoping-mode predictions of the mound response, if the mound is placed outside the surf zone. In such predictions it may be useful to investigate the mound response for a range of $K_{c}$-values to establish the sensitivity of the response to this coefficient.

The numerical simulations reproduced the mound evolution satisfactorily, although there was some discrepancy in the trough area directly shoreward of the mound. The optimum $K_{c}$-value for Cocoa Beach was significantly lower than the corresponding value found for Silver Strand. This value is in agreement with observations made in fitting the analytical model to the field data, indicating that a value of $K_{c}=0.004$ should be representative for the transport in the offshore. Again, one reason for obtaining a larger value for the Silver Strand data might be that the material was placed on top of an existing bar, where the transport activity is expected to be higher than at locations further offshore. Other reasons for the discrepancy in $K_{c}$-values between the two sites investigated might be: (1) differences in wave climate and sediment characteristics between the two sites, and (2) waves were measured at Silver Strand, but hindcasted at Cocoa Beach. More comparisons with laboratory or field data are needed before reliable values for $K_{c}$ can be established and the dependence of $K_{c}$ on different environmental factors resolved.

The difference between the analytical and numerical model in predicting the mound response for Silver Strand and Cocoa Beach was not markedly large. The constant diffusion coefficient employed in the analytical model produced a symmetric evolution of the mound that was not in agreement with the observations. A numerical model is able to describe a varying diffusion coefficient since the boundary and forcing conditions can be arbitrary. Also, the numerical model will include the entire profile that is typically of interest in more detailed studies, not only the mound region.

\section{Conclusions}

A one-dimensional mathematical model was developed for calculating the time-averaged net cross-shore transport rate and evolution of mounds placed where non- 
breaking waves prevail. At the mound, the governing equation for the cross-shore transport rate balances contributions by wave asymmetry and gravity, and the rate of change of bottom elevation is controlled or bounded by reference to an equilibrium profile. The resultant equation can be reduced to the diffusion equation for which many analytical solutions exist, if the initial, boundary, and forcing conditions can be schematized. Such solutions yield characteristic parameters controlling the evolution of a mound (or trench) subjected to wave action. The analytical model can be used to investigate the influence of various design and environmental parameters. For example, it can easily be shown that the time scale of change is directly proportional to the square of mound width, inversely proportional to wave height cubed, and directly proportional to the water depth to the three-half power. The analytical model was validated with field data on mound evolution from different sites.

The model can also be solved numerically to account for local changes in forcing and bathymetry. This was done for two of the field sites using a modified version of SBEACH where the transport in the offshore was included. The simulations results with SBEACH improved compared to the analytical model, especially on the seaward side of the mound. Also, in the numerical approach the entire beach profile is included, which yields more complete information on the profile response required in more detailed studies.

A key parameter of the analytical model, the diffusion coefficient, was determined from four data sets that span a wide range of wave conditions. Based on these limited data, an empirical formula was developed for the diffusion coefficient that should be useful in scoping-mode studies of mound analysis and design. The transport coefficient in the SBEACH model, corresponding to the diffusion coefficient in the analytical model, gave values consistent with the latter coefficient. It is concluded that the analytical model has applicability for preliminary design in determining the time scale and movement of material placed in the form of offshore linear mounds and that the numerical model can be used for more detailed investigations of mound response.

\section{Acknowledgments}

This work was partially funded under the Regional Sediment Management Program of the U.S. Army Engineer Research and Development Center, and partially by the Swedish research council Formas (Project No. 214-2009-802: The impact of climate change on coastal flooding and erosion: processes, modeling, and measures). Mr. Randall A. Wise provided the beach profile data for Cocoa Beach, FL. The review comments by Dirk-Jan Walstra and Mohamed Dabees helped to greatly improve the paper and are much appreciated.

\section{References}

Andrassy, C.J. (1991) - Monitoring of a nearshore disposal mound at Silver Strand State Park. Proceedings Coastal Sediments '91, ASCE, 1970-1984.

Barnard, P.L.; Hanes, D.M.; Lescinski, J.; Elias, E. (2007) - Monitoring and modeling nearshore dredge disposal for indirect beach nourishment, Ocean Beach, San Francisco. Proceedings $30^{\text {th }}$ Coastal Engineering Conference, ASCE, 4192-4204.

Beck, T.M.; Rosati, J.D.; Rosati, J. (2012) - An update on nearshore berms in the Corps of Engineers: Recent projects and future needs. CHETN-XIV-10, Coastal and Hydraulics Laboratory, U.S. Army Engineer Research and Development Center, Vicksburg, MS, U.S.A. Available on-line at http://www.dtic.mil/cgibin/GetTRDoc?AD=ADA559368

Bruun, P. (1954) - Coast erosion and the development of beach profiles. Technical Memorandum No. 44, Beach Erosion Board, U.S. Army Corps of Engineers. U.S.A.

Carslaw, H.; Jaeger, J. (1959) - Conduction of heat in solids. 510p., Clarendon Press, Oxford, U.K.

Crank, J. (1973) - The Mathematics of Diffusion. 2nd ed., Clarendon Press, Oxford. Available on-line at http://www.ees.nmt.edu/outside/ courses/hyd510/PDFs/SupplementaryReadings/Crank_1975_Diffusion.p df

Dally, W.R. (1992) - Random breaking waves: Field verification of a wave-by-wave algorithm for engineering application. Coastal Engineering, 16(4):369-397. DOI: 10.1016/0378-3839(92) 90060-8

Dally, W.R.; Osiecki, D.A. (2006) - Development \& validation of hindcast-driven nearshore wave information. $9^{\text {th }}$ International Workshop on Wave Hindcasting and Forecasting, Victoria, Canada.

Dean, R.G. (1977) - Equilibrium beach profiles: U.S. Atlantic and Gulf coasts. Department of Civil Engineering, Ocean Engineering Report No. 12, Univ. of Delaware, Newark, DE.

Dean, R.G. (1987) - Coastal sediment processes: Toward engineering solutions. Proceedings of Coastal Sediments '87, ASCE, 1-24.

Dean, R.G. (1991) - Principles of beach nourishment. In: Komar, P.D. (editor), Handbook of Coastal Processes and Erosion, pp.217-231, CRC Press, Boca Raton, FL, U.S.A.

DRP (1994) - Tidal constituents database - East Coast, Gulf of Mexico, and Carribean Sea. Dredging Research Technical Notes, DRP-1-13. Coastal Engineering Research Center, U.S. Army Engineer Waterways Experiment Station, Vicksburg, MS.

Foster, G.A.; Healy, T.R.; De Lange, W.P. (1996) - Presaging beach nourishment from a nearshore dredge dump mound, Mt. Maunganui Beach, New Zealand. Journal of Coastal Research, 12(2):395-405.

Grunnet, N.M.; Ruessink, B.G.; Walstra, D.J.R. (2005) - The influence of tides, wind and waves on the redistribution of nourished sediment at Terschelling, The Netherlands. Coastal Engineering, 52(7):617-631. DOI: 10.1016/j.coastaleng.2005.04.001

Hands, E.B.; Allison, M.C. (1991) - Mound migration in deeper water and methods of characterizing active and stable berms. Proceedings Coastal Sediments '91, pp.195-1999, ASCE, U.S.A.

Kobayashi, N. (1982) - Sediment transport on a gentle slope due to waves. Journal of Waterway, Port, Coastal and Ocean Engineering, 108(WW3):254-271.

Larson, M. (1996) - Model of beach profile change under random waves. Journal of Waterway, Port, Coastal, and Ocean Engineering, 122(4):172-181.

Larson, M.; Kraus, N.C. (1989) - SBEACH: Numerical Model for Simulating Storm-Induced Beach Change. Report 1: Empirical 
Foundation and Model Development. Technical Report CERC89-9, Coastal Engineering Research Center, U.S. Army Engineer Waterways Experiment Station, Vicksburg, MS, U.S.A.

Larson, M.; Kraus, N.C. (1992) - Analysis of cross-shore movement of natural longshore bars and material placed to create longshore bars. Technical Report DRP-92-5, U.S. Army Engineer Waterways Experiment Station, Vicksburg, MS, U.S.A.

Larson, M.; Kraus, N.C.; Hanson, H. (1987) - Analytical solutions of the one-line model of shoreline change. Technical Report CERC87-15, U.S. Army Engineer Waterways Experiment Station, Vicksburg, MS, U.S.A.

Larson, M.; Kraus, N.C.; Wise, R.A. (1999) - Equilibrium beach profiles under breaking and non-breaking waves. Coastal Engineering, 36(1):59-85. DOI: 10.1016/S0378-3839(98)00049-0

Madsen, O.S., (1991) - Mechanics of cohesionless sediment transport in coastal waters. Proceedings of Coastal Sediments '91, pp.15-27, ASCE, U.S.A.

Madsen, O.S. (1993) - Sediment transport on the shelf. Sediment Transport Workshop DRP TA1, Coastal Engineering Research Center, Vicksburg, MS, U.S.A.

McLellan, T.N. (1990) - Nearshore mound construction using dredged material. Journal of Coastal Research, SI7:99-107, Fort Lauderdale, FL, U.S.A. Article Stable URL: http://www.jstor.org/ stable $/ 25735392$

Niedoroda, A.W.; Reed, C.W.; Swift, D.J.P; Arato, H.; Hoyanagi, K. (1995) - Modeling shore-normal large-scale coastal evolution. Marine Geology, 126(1-4):181-199. DOI: 10.1016/00253227(95)98961-7
Otay, E.N. (1995) - Monitoring results of a nearshore disposal berm. Proceedings Coastal Dynamics '95, pp.546-558, ASCE, U.S.A.

Rosati, J.D.; Wise, R.A.; Kraus, N.C.; Larson, M. (1993) SBEACH: Numerical model for simulating storm-induced beach change. Report 3: User's manual. Instruction Report CERC-932, Coastal Engineering Research Center, U.S. Army Engineer Waterways Experiment Station, Vicksburg, MS, U.S.A.

Smith, E.R.; Gailani, J.Z. (2005) - Nearshore placed mound physical model experiment. DOER Technical Notes Collection (ERDC TN-DOER-D3), U.S. Army Engineer Research and Development Center, Vicksburg, MS, U.S.A.

Van Duin, M.J.P.; Wiersma, N.R.; Walstra, D.J.R: Van Rijn, L.C.; Stive, M.J.F. (2004) - Nourishing the shoreface: observations and hindcasting of the Egmond case, The Netherlands. Coastal Engineering, $\quad 51(8-9): 813-837 . \quad$ DOI: 10.1016/j.coastaleng.2004.07.011

Walstra, D.J.R.; Hoekstra, R.; Tonnon, P.K.; Ruessink, B.G. (2013) - Input reduction for long-term morphodynamic simulations in wave-dominated coastal settings. Coastal Engineering, 77, 5770. DOI: 10.1016/j.coastaleng.2013.02.001

Work, P.A.; Otay, E.N. (1996) - Influence of nearshore berm on beach nourishment. Proceedings $25^{\text {th }}$ Coastal Engineering Conference, pp.3722-3735, ASCE, U.S.A.

Zwamborn, J.A.; Fromme, G.A.W.; FitzPatrick, J.B. (1970) - Underwater mound for the protection of Durban's beaches. Proceedings $12^{\text {th }}$ Coastal Engineering Conference, pp.975-994, ASCE, U.S.A. 